\title{
Psychiatric effects of malaria and anti-malarial drugs: historical and modern perspectives
}

\author{
Remington L. Nevin ${ }^{1 *}$ and Ashley M. Croft ${ }^{2}$
}

\begin{abstract}
The modern medical literature implicates malaria, and particularly the potentially fatal form of cerebral malaria, with a risk of neurocognitive impairment. Yet historically, even milder forms of malaria were associated in the literature with a broad range of psychiatric effects, including disorders of personality, mood, memory, attention, thought, and behaviour. In this article, the history of psychiatric effects attributed to malaria and post-malaria syndromes is reviewed, and insights from the historical practice of malariotherapy in contributing to understanding of these effects are considered. This review concludes with a discussion of the potentially confounding role of the adverse effects of anti-malarial drugs, particularly of the quinoline class, in the unique attribution of certain psychiatric effects to malaria, and of the need for a critical reevaluation of the literature in light of emerging evidence of the chronic nature of these adverse drug effects.
\end{abstract}

Keywords: Malaria, Malariotherapy, Anti-malarial drugs, Psychiatric effects, Toxicity

\section{Background}

This review, written for the psychiatrist as much as for the malariologist, serves as an introduction to what by modern perspectives may be viewed as surprising areas of common interest. The disciplines of psychiatry and malariology were united briefly in the early to mid twentieth century in the historical practice of malariotherapy, in which patients were intentionally inoculated with malaria for its presumed therapeutic neuropsychiatric effects. Although this practice has long fallen out of favour and although the two disciplines have subsequently diverged, insights from malariotherapy and more broadly the field of malariology have continued to make important contributions to psychiatry in the modern era.

Untreated or delayed treatment of malignant Plasmodium falciparum malaria infection may result in coma. This cerebral complication of malaria is implicated particularly with lasting cognitive deficits that owing to the

\footnotetext{
*Correspondence: rnevin@jhu.edu

1 Department of Mental Health, Johns Hopkins Bloomberg School of Public Health, 624 N. Broadway, Room 782, Baltimore, MD 21205, USA Full list of author information is available at the end of the article
}

high prevalence of disease worldwide may contribute significantly to the global burden of psychiatric morbidity [1]. Yet similarly, anti-malarial drugs, particularly of the quinine-like class of quinolines commonly used in treatment and prevention of disease, are also increasingly recognized to exert potentially chronic psychiatric adverse effects that may also contribute to this global burden of morbidity [2].

This review, inspired by an earlier seminal work [3], synthesizes over a century of critical literature from psychiatry and malariology - ranging from anecdotal historical observations to evidence from modern randomized controlled trials - to explore the evolving understanding of the psychiatric effects of malaria and of anti-malarial drugs. In this review, the evolution of psychiatric effects attributed to malaria is described, from the historical perspective in which a broad range of symptoms were attributed to the disease, to the current understanding of the more limited psychiatric effects of cerebral malaria (CM) and post-malaria syndromes. Next, malariotherapy and its historical role in psychiatry are described. Lastly, the psychiatric effects of anti-malarial drugs, particularly of the quinoline class, are reviewed, including a discussion 
regarding the potential confounding effect that these may have had on symptoms historically associated with malaria.

\section{Psychiatric effects of malaria}

Although early descriptions of the psychiatric effects of malaria first appeared in the ancient medical literature of Hippocrates and Galen $[4,5]$, it was only many centuries later that descriptions of these effects became relatively common. Such descriptions grew particularly detailed in the aftermath of World War I (WWI), where malaria, epidemic on the Macedonian front between 1916 and 1918 , was unexpectedly found to be the leading cause of psychiatric disorders among soldiers of the Allied powers fighting there [6].

Detailed reports in the literature from this era described a seemingly bewildering set of psychiatric effects attributed to both severe and mild forms of the disease. Early reports had described dreamlike states [7], anterograde amnesia, difficulties with concentration, disorientation, and forgetfulness [8], confusional psychosis, dementia, "melancholia", and mania [9] emerging in patients recovering from severe malaria. During this era, mild chronic or intermittent malaria infection had also become associated with symptoms of "neurasthenia", including depression, irritability, anxiety, and insomnia [10]. In subsequent years, even more severe symptoms such as confusion [11], intermittent psychoses, and delirium were also commonly attributed to those with mild forms of malaria [12].

This literature even warned of the potential for missed diagnoses of malaria prior to the onset of malarial fever among psychiatric patients admitted for care and thought to be suffering from delirium and psychoses [13]. Many such patients were diagnosed with malaria only some time later at the onset of fever, or when their symptoms progressed to coma. These reports described a common prodrome of hallucinations, anxiety, crying, violence, agitation, and a dreamy and confusional state [13].

So common and diverse became the psychiatric effects attributed to both severe and mild forms of malaria during the post-WWI era, that an entire textbook, well received by psychiatrists at the time [14], was published with chapters featuring case reports of malarial psychoses, "dementia praecox", confusional and delusional insanity, mania, "melancholia", delirium, and dementia attributable to the disease. As noted by the author in his preface, "very few known syndromes are absent from the list apparently arising from malarial infection" [15].

By World War II (WWII), growing US and allied military experience, particularly in the South Pacific, had identified similar psychiatric effects associated with malaria. Reports from US military clinicians noted a characteristically confusional form of psychosis, as well as persecutory, grandiose, bizarre delusions, and symptoms of anxiety, depression, and mania associated with both severe and mild forms of the disease [16, 17]. Yet others had begun to challenge the true association of many of these symptoms with malaria, noting "too great a tendency to blame malaria for many of these symptoms" [16], with the temporal association of certain of these symptoms suggesting to other authors a toxic process [16].

Despite such growing suspicions, the psychiatric effects of malaria were still considered "more common than are generally known" [4], and a military journal editorial noted that malaria should be considered "associated with protean mental states" [18]. Psychiatric symptoms also remained clearly associated in the literature of the era with even the mild chronic and relapsing forms of disease, with a case report describing psychosis developing weeks prior to the onset of fevers from the generally benign Plasmodium vivax malaria [17].

Reports from among soldiers of the Vietnam War era similarly described mostly transient cases of psychosis, and impaired memory and concentration generally following admission for treatment for malaria [19], often lagging admission by some days, and typically without evidence of such symptoms while previously febrile [20]. Neuropsychological testing of certain of these patients both soon after their acute illness and following their recovery identified common patterns of deficits, particularly in tests of recent memory, visual organization, psychomotor speed, and visual motor integration [21, 22]. Decades later, follow-up of malaria patients from the Vietnam War demonstrated lasting changes in personality, depression, and symptoms of partial seizure [23], as well as deficits on tests of memory, and other evidence of chronic cognitive dysfunction on neuropsychological testing [24].

In more recent studies of broadly defined malaria infections, acute malaria among children [25], and multiple recurrent malaria infections have been associated with adverse effects on short-term cognitive performance [26]. Similarly, in recent reviews, among chronic psychiatric effects, the most common and strongest evidence exists for a risk of chronic cognitive impairment following successful malaria treatment [27-30]. Additional retrospective studies have attributed a risk of subclinical depressive and anxiety symptoms [31], as well as altered executive functioning [32], particularly following severe malaria infection.

\section{Cerebral malaria}

Unlike past usage of the term, which had been significantly broader in scope [33], and had included 
presentations that had involved organic mental syndrome and even acute personality change [21], the modern strict definition of CM has gradually evolved to require alterations in consciousness for diagnosis [34, 35]. This modern definition of $\mathrm{CM}$, which was developed for research purposes [36], and which is considered a diagnosis of exclusion [37], specifically limits use of the term to a patient with coma occurring in the presence of malignant P. falciparum malaria parasitaemia [38]. The strong and highly sensitive and specific association of such clinicallydefined CM with objective signs, including malaria retinopathy, has significantly improved diagnostic reliability $[39,40]$, particularly among children in tropical countries who are primarily affected by the disorder.

Unlike historical definitions, the modern definition of $\mathrm{CM}$ is primarily described as an acute neurological disorder and is notably less associated in the literature with acute psychiatric symptoms [33, 41]. Some authors have questioned its acute association with psychosis [42], although early case reports [43] and reviews [44] through the 1990s continued to describe self-limiting acute psychosis occurring following treatment for CM.

Prospective follow-up of patients specifically with CM are limited, but small studies of children find increased risk of cognitive deficit [45] lasting through 2 years of follow-up [46]. In children surviving CM confirmed by retinopathy, certain measures of retinopathy were associated with chronic deficits in attention and cognitive ability [40]. A prospective study of children with a spectrum of severe malaria including $\mathrm{CM}$ also found sub-acute behavioural problems and decreased attention [47].

Retrospective studies of children with $\mathrm{CM}$ also report long-term impairments in cognition and executive functioning [48] as well as developmental and cognitive impairments including in speech, language, and memory [49-51], with seizure during acute infection emerging as a strong risk factor [52]. Small retrospective studies in adults have also shown chronic impairments in verbal learning and abstract reasoning [53].

With the rise in diagnostic specificity of malaria disorders, investigators have been able to distinguish chronic sequelae of treated CM from those of other complications of malaria, including severe malarial anaemia (SMA) without coma. Consistent with the findings in other anemic disorders, children under 5 years of age with SMA have also been found to suffer long-term cognitive impairment [54].

\section{Post-malaria syndromes}

With the evolution of the definition of $\mathrm{CM}$ requiring neurological signs during acute $P$. falciparum parasitaemia for diagnosis, three additional disorders have been defined to describe cases in which neuropsychiatric sequelae become manifest primarily following treatment and resolution of acute malaria infection, independent of the severity of prior disease, including occasionally occurring following illness from benign $P$. vivax infection. One disorder has been referred to as delayed cerebellar ataxia (DCA) [55], or in some cases as related delayed cerebellar syndromes $[56,57]$. A later somewhat distinct disorder has been referred to as post-malaria neurological syndrome (PMNS) [58] while a related disorder of acute disseminated encephalomyelitis (ADEM) has been defined which is diagnosed with the aid of neuroimaging studies. Although disagreement has been raised as to whether certain of these constitute unique disorders [59], they appear to differ from each other and from the modern disorder of CM in regards to the latency, frequency, and type of reported psychiatric findings.

Although psychiatric symptoms are only rarely associated with delayed cerebellar syndromes in the literature, when reported, these have included giddiness [56], alterations in attention [60], and word-finding difficulties [61].

Similarly, in cases of ADEM, although neurological findings tend to predominate, psychiatric symptoms including alterations in sensorium [62], confusion [63], disorientation [64], and language difficulties have been reported [65].

In contrast to ADEM and the delayed cerebellar syndromes, psychiatric symptoms have been far more commonly reported with PMNS, to include the broader range of symptoms historically associated with malaria infections, including anxiety [66], temporospatial disorientation [67], difficulties with word-finding [68], acute confusion [69], mood changes, [70], psychosis with hallucinations, persecutory delusions, and mania [58], and disturbances in behaviour [71].

\section{Malariotherapy of psychiatric disease}

Ancient knowledge of the psychiatric effects of malaria included accounts describing reductions in aggressiveness among the mentally ill after bouts of malaria [72]. In the early twentieth century, growing awareness of the reported psychiatric effects of malaria, and recognition that febrile illness had proven therapeutic in the treatment of neurosyphillis [73] - a debilitating and epidemic condition then known as "general paresis" for which no effective treatments were then available [74] - prompted the first formal experimentation with the practice of malariotherapy.

According to the first published description of the practice [75], for which its author would subsequently win the Nobel Prize in medicine [76-78], neurosyphillis patients were intentionally inoculated with blood-stage benign forms of malaria, allowing upwards of ten cycles, 
or paroxysms, of intermittent fever prior to treatment of the infection with available anti-malarial drugs [75].

Early case reports of this technique described common and pronounced improvements in psychiatric symptoms including reduced irritability, aggression, mania, psychosis, confusion, amnesia, and disorientation following such fever treatment [75, 79-84]. Complete cures, later categorized as remissions by some authors $[85,86]$, were initially reported in up to a third of patients. Partial cures were reported in about a half [87], although subsequent reports claimed somewhat greater risks and more mixed success rates [86, 88-93]. Intriguingly, following the termination of fever paroxysms by treatment with available anti-malarial drugs, a distinct mental state described as "paraphrenic" or late psychosis was occasionally described with transient confusional, delusional, incoherent, hallucinatory, and manic-depressive features [94].

So common became the practice of malariotherapy soon after its introduction that concerns of autochthonous spread of malaria led to health ministries establishing standard guidelines for the practice [95], including the enforcement of vector controls in the vicinity of patients $[96,97]$. Although mosquito inoculation, rather than blood-stage inoculation, had been recognized as associated with a risk of malaria relapse [98], and to thus pose an increased risk of autochthonous spread, the growing popularity of malariotherapy for the treatment of non-syphilitic psychiatric patients [99], together with concerns regarding cross-contamination with Treponema pallidum, led to increasing use of direct mosquito inoculation for the purpose $[85,100,101]$.

Subsequent experience would demonstrate that the results of treatment of other psychiatric disorders (including chronic "dementia praecox" or schizophrenia, as well as manic-depressive psychosis) were mixed and perceived as less successful [73, 94] and with the development of effective antibiotics for treatment of neurosyphillis, the practice of malariotherapy gradually fell into disuse.

\section{Psychiatric effects of anti-malarial drugs}

Although many classes of drug have wide clinical applications as anti-malarials and also are known to cause psychiatric effects, the quinoline derivatives are unique in medical history for having been used ubiquitously to treat and prevent malaria, often to the exclusion of other classes of drug. For example, with few alternatives, prior to WWI, malaria was invariably treated and prevented with quinine, or occasionally with one of the other naturally occurring quinoline-based cinchona alkaloids [102, 103]. Similarly, in the aftermath of WWI and through WWII, the only other anti-malarials that came into reliable use were synthetic quinolines initially developed by German scientists [102].

It was only in the decades following WWII, with the gradual development and deployment of drugs of alternative classes, to include proguanil and pyrimethamine [102], the discovery of the anti-malarial activity of tetracyclines [104, 105], and recently, the isolation of naturally-occurring qinghaosu [106], or artemisinin, from Artemisia annua [107, 108], that effective and widely used alternatives to the quinolines emerged both for prevention and treatment of disease.

While the quinolines have remained in common use through the present day, unlike these newer anti-malarial classes, the utility of certain members of the quinoline class in treating and preventing malaria has become progressively compromised through rising awareness of symptoms of idiosyncratic intoxication and central nervous system (CNS) toxicity associated with their use. Suggestive of a broad class effect spanning common structural variations, anti-malarial quinolines with psychiatric effects that are commonly described in the literature include the naturally occurring 4-quinolinemethanol cinchona alkaloids quinine and quinidine, whose use as anti-malarials predominated prior to WWII; the synthetic acridine derivative quinacrine (which may be considered a ring-substituted 4-aminoquinoline), whose use reached a peak during that war; the synthetic 4-aminoquinolines including chloroquine, whose use expanded widely following WWII; the synthetic 4-quinolinemethanol mefloquine, developed in the aftermath of the Vietnam War and whose use took the place of chloroquine throughout the 1980s and 1990s, and the synthetic 8 -aminoquinolines, which have been used sporadically since their first development following WWI, but which are now being considered for expanded use in global malaria control efforts.

\section{Quinine and the cinchona alkaloids}

The earliest human experience with the quinolines dates to discovery of the naturally-occurring drug quinine, a 4-quinolinemethanol alkaloid first isolated from the bark of the Cinchona tree in the seventeenth century, together with the related cinchona alkaloid quinidine [109]. Although reports from the early twentieth century noted that quinine could have significant psychiatric effects [11], including causing depression, mania, irritability and personality change [110], and that these might not be distinguished from those attributed to disease [7], only relatively recently has it become clear that quinine, independent of malaria infection, may cause a serious toxic state marked by symptoms including delirium and confusion $[111,112]$. 
In contrast, a broader range of psychiatric effects specifically due to quinidine have been widely reported in the literature, including mood change [113], auditory hallucinations [114, 115], visual hallucinations and delusions $[115,116]$, paranoia $[116,117]$, confusion, and delirium $[116,118]$.

\section{Quinacrine}

Quinacrine, a derivative of acridine dye first synthesized in the early 1930s [119], marketed initially under the names erion and atabrine [120], then later also under the name Mepacrine [121], may be considered a ring substituted 4-aminoquinoline. In early reports of its use, it was noted to induce "definite cases of delirium and mental disturbances" [122], including symptoms of depression [123], and delusional insanity. Case reports described acute personality and behavioural change, severe insomnia and anxiety described as an "impression of impending death" [124], visual hallucinations, and cognitive dysfunction. One patient complained that "a large part of his brain was out of action" [124], while another patient was described as manic, restless, disoriented, and suffering visual hallucinations that "snakes and fantastic animals were crawling on the floor" [125].

Although early marketing materials for the drug acknowledged "mental disturbances which have been observed in a few instances during treatment" [126], it was also emphasized that disorders of the nervous system, including sudden delirium and delusional insanity, were "not infrequent in the course of acute malarial fevers" [126], and that it was "important to distinguish between those due to malaria itself and those which may be attributable to the drug" [126].

With shortages of quinine during WWII, quinacrine was added to the US pharmacopoeia in 1942 [127], and was quickly prioritized for military use both as treatment and as a suppressive prophylaxis throughout the war [128]. Although studies of the acute toxicity of quinacrine had been planned during a wartime anti-malarial drug development effort [129], these were soon deprioritized after they were declared to be of "minor importance" to military leadership [130]. Although early studies in the UK had suggested that quinacrine caused "troublesome dreams" [131], and independent studies in the US had noted slight increases in nervousness [132], it was initially unclear whether such presumed toxic effects were actually due to quinacrine or merely to a contaminant $[128,133]$.

Towards the end of the war, however, sufficient experience had accumulated, including from rechallenge experiments, for wartime researchers to conclude that quinacrine use was definitely associated with a toxic psychosis distinct from the effects of malaria, often of abrupt onset [134, 135], described as including "mania, catatonia, and paranoid and hallucinatory states" [136], and typically developing only several days after the start of treatment [134]. Authors noted the psychosis was typically marked either by "excitement, hallucinations, and delusions" with an affect of "euphoria and expansiveness" [137], or alternatively with "retardation, disorientation, and amnesia to recent events, together with confabulation" [137], where affect was predominantly "one of bewilderment and fearfulness" [137].

In controlled tests of intellectual functioning, a large proportion of subjects administered quinacrine were found to suffer significant subclinical impairment, and in two cases of psychosis that developed subsequently, tests of intellectual functioning had showed mild impairment prior to onset [138]. The authors concluded that "among a large group" administered quinacrine, "some would show clinical confusion" [139]. A separate controlled study conducted among healthy US military physicians clearly demonstrated quinacrine induced changes in the electroencephalograph [140], accompanied by apprehension, restlessness, insomnia, "awakening dreams which at times were of frightening and nightmare quality" [141], and symptoms of mania described as "an unusual push of activity" associated with "tension, irritability, and anxiety" [142]. One subject experiencing panic attack and flight of ideas noted he "felt so bombarded by stimuli that he could not deal with them effectively" [141]. The patient became very anxious, depressed, confused, and was thought to be suffering delirium, although his consciousness was in fact preserved [141, 142].

With the publication of such research findings initially restricted due to wartime considerations, official documents acknowledged only that "psychological disturbances occasionally appear" with use of quinacrine [143], and that the drug could cause "mild excitement" and rarely, "acute maniacal psychoses" [144]. Despite the imprecision of official reports, quinacrine was nonetheless recognized by numerous wartime physicians as a potential cause of psychiatric disorders [145], and as the war ended and in subsequent years as restrictions were rescinded, numerous publications appeared describing psychiatric effects associated with the drug's use.

One ecological study linked an increase in a combat unit's rate of psychoses to their initiation of quinacrine for prophylaxis [146]. A case report described a previously healthy soldier suffering three distinct episodes of mania, each occurring with recurrent use of quinacrine both for prophylaxis and treatment [147]. Another detailed case report described a patient initially free of psychiatric history and thought to be suffering from cerebral malaria, who following 5 days of treatment with quinacrine developed excitement, talkativeness, and 
rambling, progressing to depression, impaired concentration, disorientation in time and place, anterograde and retrograde amnesia, and delusions. These symptoms lasted 2 weeks [148]. One case series of those treated with quinacrine reported psychoses developing 0-10 days after the last day of malarial fever [149]; another between 3-12 days following the start of quinacrine [137]; while another reported an even wider latency of onset of 2-22 days, with a similarly wide range in time to satisfactory recovery of 1-30 days. Of significance, in at least four cases in the series, failure to recover and the development of chronic psychiatric disorders was noted [135].

In the immediate postwar years, a few additional studies and case reports of psychiatric effects from quinacrine were also published [150], including a series describing inappropriate sexual behaviour associated with psychoses [151]. In a final published study of 31 previously healthy Army Medical Department officers who volunteered to take the drug experimentally at treatment doses [152], 77 \% suffered some form of mental disturbances: $71 \%$ complained of abnormal, anxious and disturbing and rarely terrifying dreams; $58 \%$ developed sleep disturbances, with loss of up to half of normal sleep, prompting sedative use to treat insomnia in two-fifths of these, or $26 \%$ of the total; $39 \%$ went on to develop severe psychic disturbances, of which a quarter, of $10 \%$ of the total, suffered frank psychoses with delusions, hallucinations, and profound changes in mood, including mania; $35 \%$ complained of tension; $32 \%$ complained of restlessness, and $29 \%$ depression. During an earlier phase of the trial when the drug had been administered at lower prophylactic dose rates, $29 \%$ had noted mild complaints, most significantly abnormal dreams and sleep disturbances, which were deemed "the most reliable warning sign" of the development of "more severe reactions" [152]. Intriguingly, it was reported that during earlier widespread use of the drug, such "minor toxic symptoms of restlessness, insomnia, and increased dreaming might frequently have passed unnoticed as a manifestation of malaria" [152].

\section{Chloroquine and other 4-aminoquinolines}

Chloroquine, a 4-aminoquinoline, was also first synthesized in the 1930s by German scientists, who named it resochin [153, 154]. Expecting a quinacrine-like effect in initial clinical testing, presumably owing to the drugs' structural similarities, its toxicity was described as being "so great in comparison to its effect" [155], that the drug was deemed "too toxic for practical use in humans" [153] and further German development was abandoned. The drug was rediscovered only during the subsequent US WWII drug development effort [154], where it was initially referred to as SN-7618. Chloroquine was investigated during this WWII era effort only after the potential utility of a related 4-aminoquinoline, sontochin, later referred to as SN-6911, was noted following the Allied invasion of Tunisia, where it was found that the drug was undergoing clinical testing by Axis-affiliated French researchers [153].

In the WWII era of US testing, sontochin was noted to induce acute confusional psychosis and nervousness at high doses [156], and in postwar testing, was found to induce a wider variety of psychiatric symptoms, including anxiety, nervousness, a sensation of "being on edge", irascibility, and irritability at lower prophylactic dose rates [157]. In contrast, during similar testing, chloroquine appeared to have only "minor toxic manifestations" [158], and in published WWII era trials, appeared devoid of psychiatric effects. Considered more effective and less toxic than sontochin during the WWII development effort [153], chloroquine was also considered "better" than quinacrine, and "much better" than quinine [159], and by the early 1950s it had begun to replace both drugs for the treatment and prophylaxis of malaria [160-162].

With increasing use however, chloroquine came to be associated with similar idiosyncratic cases of toxicity as those noted previously with the cinchona alkaloids and with quinacrine and sontochin. These took the form of various psychiatric symptoms including sleep disturbances and insomnia [163-165], mood and personality change $[165,166]$, impulsivity, flight of ideas, and inappropriate behaviour $[165,167]$, persecutorial and paranoid delusions $[165,168]$, delusional misidentification $[169,170]$, depersonalization [166], visual and auditory hallucinations [165, 171], and mania [172, 173]. Suicidality [167] and completed suicide [174-176] were also not uncommonly reported. Although psychiatric symptoms from chloroquine have been noted to often resemble a brief psychotic or delusional disorder [177-179], on careful evaluation they are more likely to feature visual hallucinations, derealization, restlessness, agitation, and anxiety than other cases of psychosis [180].

A case of severe psychosis with features of depersonalization and anxiety that developed under controlled research settings following chloroquine therapy for induced malaria was causally attributed by the researchers to the drug and not to malaria disease; following resolution of psychosis the patient experienced difficulties with concentration that lasted 4 months [181]. A separate case of transient amnesia linked to the drug, [182], and difficulties with concentration [183], confusion [184], delirium, and catatonia [165, 185] have also been reported.

\section{Mefloquine}

Mefloquine is a synthetic 4-quinolinemethanol analogue of quinine that was developed by the US military amid 
concerns of rising chloroquine resistance during the Vietnam War [186] through a subsequent drug development effort similar to that of the earlier WWII era [187] that spanned the 1960s-1980s [188]. Although once commonly considered the drug of choice for treatment and prophylaxis of malaria and marketed under the trade name Lariam, use of mefloquine has been severely limited by awareness of significant idiosyncratic CNS toxicity [189] which, as with quinacrine [152], has been found to affect a sizeable minority of users at prophylactic dosages and a majority of users at treatment dosages [189]. According to recent European product labelling [190], very commonly reported psychiatric effects occurring in $>10 \%$ of prophylactic users of mefloquine include abnormal dreams and insomnia, while commonly reported psychiatric effects occurring in 1-10\% of prophylactic users include anxiety and depression.

As with earlier generations of quinoline anti-malarials, and consistent with product label warnings of encephalopathy, case reports of psychiatric effects from mefloquine typically describe a complex and diverse range of effects on mood, personality, thought, cognition, sleep, and behaviour [191]. These include asthenia [192], melancholia [193], anxiety [194], phobias [195, 196], feelings of unrest [197, 198], paranoia [199], increased self-esteem [200, 201], impaired judgment [198], social disinhibition [192, 202], giddiness [203], altered sexual libido [204], manic behaviour and paranoid delusions or psychosis [194, 200, 202, 204], hyperreligiosity [204], depersonalization $[192,198,205]$, concentration and cognitive problems [197], problems with word finding [201], disorientation [193, 198, 206], symptoms of amnesia and confusion or disorientation [192, 193, 203], sleep disorders [207, 208], severe nightmares, [209] sleep paralysis and "flashbacks" [201], suicidal ideation [210], and suicide [176, 211-213].

On initial presentation, individuals suffering from these diverse effects may appear to be suffering from a potentially wide range of psychiatric disorders that span the diagnostic nosology, to include anxiety, depressive, bipolar, psychotic, dissociative, personality, conversion, and factitious disorders $[189,191,198]$. In particular, the psychiatric effects of mefloquine have been noted to potentially confound the diagnosis of a number of psychiatric disorders prevalent in military settings, including posttraumatic stress disorder [189, 214].

Severe and life-threatening psychiatric symptoms from mefloquine, including suicidal ideation and suicide, may be preceded by often subtle prodromal symptoms including even mild disturbances in sleep and dreaming [215]. Although such symptoms have often previously been attributed to other causes and their critical significance overlooked even by influential authorities [216-218], both the European and US product labelling now explicitly direct the discontinuation of the drug at the onset of any psychiatric symptom [190]. Even the earliest approved US mefloquine product insert appeared to echo the conclusions of prospective studies of quinacrine conducted decades earlier [152] listing "anxiety, depression, restlessness or confusion" as potentially prodromal to a "more serious event" and requiring the drug's discontinuation [190].

Similarly, while psychiatric symptoms from mefloquine were previously considered reversible and self-limiting, the US product label for mefloquine was recently updated to include a boxed warning (or "black box") that psychiatric effects from mefloquine could last years after use [219]. A recent follow-up study has found a sizeable proportion of those previously reporting adverse events from the drug complain of long-term psychiatric symptoms including cognitive dysfunction years after use [220]. Mefloquine has been convincingly linked to an increased risk of PMNS [58, 221], and a number of reviews have observed that certain psychiatric symptoms observed following malaria might plausibly be due to this and related quinoline anti-malarials [36, 44].

\section{8-Aminoquinolines}

The 8-aminoquinolines were among the first synthetic quinoline anti-malarials. Pamaquine (also known as plasmochin), developed by German scientists [222, 223], and in use since the 1920s [224] was initially thought to be free of CNS toxicity, but a fatal case of fatal human toxicity, marked by symptoms of apprehension and restlessness, revealed evidence of extensive brain and brainstem neurotoxicity [225]. By the late 1940s, other synthetic 8 -aminoquinoline anti-malarials in common use prior to WWII, or introduced during the WWII drug development effort, had been linked to a severe neurotoxic syndrome [226-228], potentially masking more subtle psychiatric effects, such as previously reported mild psychosis $[229,230]$.

Primaquine, the only synthetic 8-aminoquinoline to safely emerge from the post-WWII era drug development program, although long considered safe and only rarely associated with psychiatric adverse effects [231], has been linked to rare reports of confusion, amnesia, and depression [232, 233]. Similarly, symptoms reported with the experimental 8-aminoquinoline tafenoquine, originally developed by the US military and now in latestage development [234] and anticipated for use both as a replacement for mefloquine and primaquine $[235,236]$ and in mass drug administration campaigns for global malaria control [234] have been described in randomized trials as similar to those of chloroquine [237]. In a recent blinded trial, tafenoquine was found to cause a slightly 
higher incidence of psychiatric symptoms than mefloquine, including abnormal dreams, agitation, anxiety, amnesia, and paranoia [238], with other reported symptoms including insomnia and depression [239].

\section{Other anti-malarials}

In contrast to the quinoline class of anti-malarials, there is a paucity of data on the psychiatric effects of newer anti-malarial classes, including the tetracyclines, and artemisinins. What evidence does exists suggests these drugs cause a narrower range, and typically fewer and less extreme psychiatric symptoms than do the antimalarial quinolines.

For example, in contrast to trials of tetracycline in combination with mefloquine [240], early trials of tetracycline monotherapy for treatment of malaria reported no psychiatric adverse effects [104]. Early trials of minocycline monotherapy for treatment and prophylaxis also reported no psychiatric adverse effects [241]. Indeed, reviews of the use of tetracyclines [242] and specifically doxycycline [243] in malaria do not specifically mention adverse psychiatric effects, and one recent review suggested these are "nearly nonexistent" [244]. Despite this, a number of studies comparing doxycycline to mefloquine report psychiatric symptoms such as insomnia and nightmares occurring, albeit less commonly than with mefloquine $[245,246]$. Additionally, a recent case series has directed attention to the potential for rare anxiety and suicidality from doxycycline [247].

In contrast, pyrimethamine, typically used in combination with sulfadoxine, appears to have few psychiatric effects. Recent reviews do not specifically mention adverse psychiatric effects from the drug [248, 249], although early observational studies suggested the combination presented a risk of insomnia and depression, although less commonly than from quinoline anti-malarials [250]. A recent trial of sulfadoxine-pyrimethamine against mefloquine also noted sleep disturbance occurring with use of the drug, although similarly less commonly than with mefloquine [251].

Likewise, the drug combination atovaquone-proguanil, commonly marketed under the trade name Malarone ${ }^{\circledR}$, also appears to have few psychiatric effects. As with the other drugs mentioned in this section, recent reviews also do not specifically mention adverse psychiatric effects from the drug [252]. Although one review suggested that atovaquone-proguanil is "the best tolerated of all antimalarial medications", psychiatric symptoms, particularly sleep disturbance and abnormal dreams, do occur with use of the drug, although again less commonly than with quinoline anti-malarials including mefloquine [253] and chloroquine-proguanil [254]. Additionally, and unlike as is the case with mefloquine [190] and with quinacrine before it [152], such psychiatric symptoms from atovaquone-proguanil are not considered prodromal or predictive of more serious neuropsychiatric adverse effects, and do not mandate discontinuation of the drug at their onset.

Lastly, and particularly given suggestive evidence of CNS toxicity from the artemisinins [255-259], psychiatric effects from anti-malarials of this class, including the semi-synthetic derivatives artemether, artesunate, and dihydroartemisinin, should be considered plausible in spite of a paucity of observational and experimental evidence of this effect. The ascertainment of psychiatric effects from the artemisinins is made particularly challenging both by their widespread use in the treatment of symptomatic malaria [260, 261], and by their ubiquitous combination with other anti-malarial drugs, including the quinoline drugs amodiaquine and piperaquine [262], which are themselves not well studied for psychiatric effects. Although a recent systematic review found consistently higher rates of psychiatric effects, particularly sleep disturbances, with artemisinin-based combination therapies containing mefloquine than with those containing other drugs, these cited studies were not designed to assess the unique effects of artemisinins [260], and no prospective studies have assessed the psychiatric effects of artemisinin monotherapy alone.

\section{Conclusions}

This review has demonstrated that malaria, regardless of its severity, has historically been associated in the literature with certain common psychiatric effects that resemble those now known to be caused by certain antimalarial drugs. This review has also demonstrated that as awareness of the adverse psychiatric effects of antimalarial drugs has grown in the modern era, the number of psychiatric effects commonly attributed in the literature to malaria, and particularly to less severe forms of the disease, has steadily decreased.

Earlier historical eras, when the psychiatric effects of malaria were considered far broader than they are today, coincided with a period of ubiquitous exposure to quinolines, both as prophylaxis and in subsequent treatment of disease. Similarly, more modern eras, in which the psychiatric effects of malaria have been generally considered to be more limited, have coincided with a period of more widespread use of alternative classes of anti-malarial drugs less commonly associated with psychiatric effects. This ecological trend suggests the distinct possibility that some psychiatric effects previously attributed to malaria may have been due in whole or in part to the effects of quinoline anti-malarials.

While malaria, and particularly in its modern definition of $\mathrm{CM}$, is undoubtedly associated with a risk of cognitive 
impairment, the insights presented in this article should draw attention to the potentially significant confounding effects of anti-malarial exposure in the causal attribution of certain other psychiatric symptoms unique to malaria. This suggests a need to critically reevaluate the existing evidence base for the potential effects of such confounding.

The insights presented here should also underscore the importance both of designing future studies of the psychiatric effects of malaria to control for such confounding as much as is feasible, and also of more thoroughly assessing and characterizing those effects potentially attributable to anti-malarials, including those drugs currently under development and testing, and planned for use in global malaria control efforts, informed by knowledge of their common adverse psychiatric effects.

\section{Abbreviations}

ADEM: acute disseminated encephalomyelitis; CM: cerebral malaria; CNS: central nervous system; DCA: delayed cerebellar ataxia; PMNS: post-malaria neurological syndrome; SMA: severe malarial anaemia; WWI: World War l; WWII: World War II.

\section{Authors' contributions}

RLN drafted the manuscript. AMC critically revised the manuscript. Both authors read and approved the final manuscript.

\section{Author details}

${ }^{1}$ Department of Mental Health, Johns Hopkins Bloomberg School of Public Health, 624 N. Broadway, Room 782, Baltimore, MD 21205, USA. ${ }^{2}$ School of Pharmacy and Biomedical Science, University of Portsmouth, James Watson Building (West), Portsmouth, Hants PO1 2FR, UK.

\section{Acknowledgements}

None.

\section{Competing interests}

Both authors report being retained as consultants and expert witnesses in legal cases involving claims of anti-malarial drug toxicity. Both authors report no other relevant financial or other competing interests.

\section{Availability of data and materials}

Historical references cited by the authors are available upon request.

\section{Consent for publication}

Not applicable.

\section{Ethics approval and consent to publish}

This article is based on previously conducted studies and does not involve any new studies of human or animal subjects performed by any of the authors.

\section{Funding}

Both authors report no grant funding or other financial support to acknowledge.

Received: 17 February 2016 Accepted: 15 June 2016 Published online: 22 June 2016

\footnotetext{
References

1. Vos T, Flaxman AD, Naghavi M, Lozano R, Michaud C, Ezzati M, et al. Years lived with disability (YLDs) for 1160 sequelae of 289 diseases and injuries 1990-2010: a systematic analysis for the Global Burden of Disease Study 2010. Lancet. 2012;380:2163-96.
}

2. Pollach $\mathrm{G}$. Neurotoxicity of quinoline-related anti-infectives: an underestimated burden of the health care systems in Africa? Gesundheitsökonomie Qual. 2013;19:109-13 (in German).

3. Weiss MG. The interrelationship of tropical disease and mental disorder: conceptual framework and literature review (Part I-malaria). Cult Med Psychiatry. 1985;9:121-200.

4. Arieti S. Histopathologic changes in cerebral malaria and their relation to psychotic sequels. Arch Neurol Psychiatry. 1946;56:79-104.

5. Anderson WK. Malaria in history. In: Malarial psychoses and neuroses. London: Oxford University Press; 1927. p. 9-16.

6. Forrester A. Malaria and insanity. Lancet. 1920;195:16-7.

7. Chavigny M. Nervous and mental complications of malaria. Encephale. 1912;7:387-91 (in French).

8. Carlill H. Korsakow's psychosis in association with malaria. Lancet. 1917:189:648-50.

9. Paisseau G. Malaria during the war. Lancet. 1919;193:749-51.

10. Pope C. Chronic malarial cachexia and its relation to neurasthenoid conditions. Boston Med Surg J. 1914;170:193-7.

11. Papastratigakis G. Mental confusion from malaria. Encephale. 1922;17:105-9 (in French).

12. Turner $\mathrm{C}$. The neurologic and psychiatric manifestations of malaria. South Med J. 1936:29:578-86.

13. Masson CB. The effect of malaria on the nervous system with special reference to the malarial psychoses. Am J Med Sci. 1924;168:334-71.

14. Review Book. Malarial psychoses and neuroses; their medical, sociological and legal aspects. J Neurol Psychopathol. 1927;8:84-5.

15. Anderson WK. Malarial psychoses and neuroses. London: Oxford University Press; 1927. p. i-vii.

16. Arbuse DI. Neuropsychiatric manifestations in malaria. US Nav Med Bull. 1945:45:304-9.

17. Boshes B. Neuropsychiatric manifestations during the course of malaria. Arch Neurol Psychiatry. 1947;58:14-27.

18. Journal of the Royal Army Medical Corps. Editorial. Psychiatry. J R Army Med Corps. 1945;84:81-2.

19. Heiman EM. More on cerebral malaria. Am J Psychiatry. 1968;125:706.

20. Blocker W, Kastl AJ, Daroff RB. The psychiatric manifestations of cerebral malaria. Am J Psychiatry. 1968;125:192-6.

21. Daroff RB, Deller JJ, Kastl AJ, Blocker WW. Cerebral malaria. JAMA. 1967;202:679-82.

22. Kastl AJ, Daroff RB, Blocker WW. Psychological testing of cerebral malaria patients. J Nerv Ment Dis. 1968;147:553-61.

23. Varney NR, Roberts RJ, Springer JA, Connell SK, Wood PS. Neuropsychiatric sequelae of cerebral malaria in Vietnam veterans. J Nerv Ment Dis. 1997:185:695-703.

24. Richardson ED, Varney NR, Roberts RJ, Springer JA, Wood PS. Long-term cognitive sequelae of cerebral malaria in Vietnam veterans. Appl Neuropsychol. 1997:4:238-43.

25. Fernando SD, de Silva D, Wickremasinghe R. Short-term impact of an acute attack of malaria on the cognitive performance of schoolchildren living in a malaria-endemic area of Sri Lanka. Trans R Soc Trop Med Hyg. 2003;97:633-9.

26. Fernando SD, Gunawardena DM, Bandara MRSS, De Silva D, Carter R, Mendis KN, et al. The impact of repeated malaria attacks on the school performance of children. Am J Trop Med Hyg. 2003;69:582-8.

27. Fernando SD, Rodrigo C, Rajapakse S. The, "hidden" burden of malaria: cognitive impairment following infection. Malar J. 2010;9:366.

28. Gay F, Zougbédé S, N'Dilimabaka N, Rebollo A, Mazier D, Moreno A. Cerebral malaria: What is known and what is being researched. Rev Neurol (Paris). 2012;168:239-56

29. de Miranda AS, Brant F, Machado FS, Rachid MA, Teixeira AL. Improving cognitive outcome in cerebral malaria: insights from clinical and experimental research. Cent Nerv Syst Agents Med Chem. 2011;11:285-95.

30. Kihara M, Carter JA, Newton CRJC. The effect of Plasmodium falciparum on cognition: a systematic review. Trop Med Int Heal. 2006;11:386-97.

31. Dugbartey AT, Dugbartey MT, Apedo MY. Delayed neuropsychiatric effects of malaria in Ghana. J Nerv Ment Dis. 1998;186:183-6.

32. Kariuki SM, Abubakar A, Newton CR, Kihara M. Impairment of executive function in Kenyan children exposed to severe falciparum malaria with neurological involvement. Malar J. 2014;13:365.

33. Newton CR, Hien TT, White N. Cerebral malaria. J Neurol Neurosurg Psychiatry. 2000;69:433-41. 
34. Wintrob RM. Malaria and the acute psychotic episode. J Nerv Ment Dis. 1973;156:306-17.

35. Marsden PD, Bruce-Chwatt LJ. Cerebral malaria. In: Hornabrook R, editor. Topics on tropical neurology. Philadelphia: F.A. Davis Company; 1975. p. 29-44.

36. Mishra SK, Newton CRJC. Diagnosis and management of the neurological complications of falciparum malaria. Nat Rev Neurol. 2009;5:189-98.

37. Idro R, Jenkins NE, Newton CRJC. Pathogenesis, clinical features, and neurological outcome of cerebral malaria. Lancet Neurol. 2005:4:827-40.

38. WHO. Guidelines for the treatment of malaria. 3rd ed. Geneva: World Health Organization; 2014

39. Postels D, Birbeck G. Cerebral malaria. Handb Clin Neurol. 2013;114:91-102.

40. Boivin MJ, Vokhiwa M, Sikorskii A, Magen JG, Beare NAV. Cerebral malaria retinopathy predictors of persisting neurocognitive outcomes in Malawian children. Pediatr Infect Dis J. 2014;33:821-4.

41. Pender E, Newman J. Malaria in children. Pediatr Emerg Care. 1990;6:40-2.

42. Osuntokun BO. Malaria and the nervous system. Afr J Med Med Sci. 1983;12:165-72.

43. Sowunmi A. Psychosis after cerebral malaria in children. J Natl Med Assoc. 1993;85:695-6.

44. Garg RK, Karak B, Misra S. Neurological manifestations of malaria: an update. Neurol India. 1999;47:85-91.

45. Boivin MJ, Bangirana P, Byarugaba J, Opoka RO, Idro R, Jurek AM, et al. Cognitive impairment after cerebral malaria in children: a prospective study. Pediatrics. 2007;119:e360-6.

46. John CC, Bangirana P, Byarugaba J, Opoka RO, Idro R, Jurek AM, et al. Cerebral malaria in children is associated with long-term cognitive impairment. Pediatrics. 2008;122:e92-9.

47. Bangirana P, Musisi S, Boivin MJ, Ehnvall A, John CC, Bergemann TL, et al. Malaria with neurological involvement in Ugandan children: effect on cognitive ability, academic achievement and behaviour. Malar J. 2011;10:334.

48. Holding PA, Stevenson J, Peshu N, Marsh K. Cognitive sequelae of severe malaria with impaired consciousness. Trans R Soc Trop Med Hyg. 1999;93:529-34.

49. Carter JA, Mung'ala-Odera V, Neville BGR, Murira G, Mturi N, Musumba $C$, et al. Persistent neurocognitive impairments associated with severe falciparum malaria in Kenyan children. J Neurol Neurosurg Psychiatry. 2005:76:476-81.

50. Carter JA, Ross AJ, Neville BGR, Obiero E, Katana K, Mung'ala-Odera V, et al. Developmental impairments following severe falciparum malaria in children. Trop Med Int Health. 2005;10:3-10.

51. Birbeck GL, Taylor TE. Severe malaria: still counting the costs. J Neurol Neurosurg Psychiatry. 2005;76:467-8

52. Idro R, Carter JA, Fegan G, Neville BGR, Newton CRJC. Risk factors for persisting neurological and cognitive impairments following cerebral malaria. Arch Dis Child. 2006;91:142-8.

53. Peixoto B, Kalei I. Neurocognitive sequelae of cerebral malaria in adults: a pilot study in Benguela Central Hospital, Angola. Asian Pac JTrop Biomed. 2013;3:532-5.

54. Bangirana P, Opoka RO, Boivin MJ, Idro R, Hodges JS, Romero RA, et al. Severe malarial anemia is associated with longterm neurocognitive impairment. Clin Infect Dis. 2014;59:336-44.

55. Senanayake N. Delayed cerebellar ataxia: a new complication of falciparum malaria? BMJ. 1987;294:1253-4

56. de Silva HJ, Gamage R, Herath HK, Abeysekera DT, Peiris JB. A delayed onset cerebellar syndrome complicating falciparum malaria. Ceylon Med J. 1986;31:147-50.

57. Senanayake $\mathrm{N}$, de Silva HJ. Delayed cerebellar ataxia complicating falciparum malaria: a clinical study of 74 patients. J Neurol. 1994;241:456-9.

58. Nguyen TH, Day NP, Ly VC, Waller D, Mai NT, Bethell DB, et al. Postmalaria neurological syndrome. Lancet. 1996;348:917-21.

59. Dollow S. Neurological sequelae of cerebral malaria. Lancet. 1996;348:1658-9.

60. Sakaria A, Mahajan S, Desai R, Shah K. Delayed cerebellar ataxia: a rare self limiting complication of Plasmodium falciparum malaria. Adv Biomed Res. 2013;2:27.
61. Duque V, Seixas D, Ventura C, da Cunha S, Meliço-Silvestre A. Plasmodium falciparum malaria, bilateral sixth cranial nerve palsy and delayed cerebellar ataxia. J Infect Dev Ctries. 2012;6:290-4.

62. Rachita S, Satyasundar M, Mrutunjaya D, Birakishore R. Acute disseminated encephalomyelitis (ADEM) - a rare complication of falciparum malaria. Indian J Pediatr. 2012;80:499-501.

63. Agrawal A, Goyal S. Acute demyelinating encephalomyelitis in a child following malaria. Indian Pediatr. 2012;49:922-3.

64. Koibuchi T, Nakamura T, Miura T, Endo T, Nakamura H, Takahashi T, Kim HS, et al. Acute disseminated encephalomyelitis following Plasmodium vivax malaria. J Infect Chemother. 2003;9:254-6.

65. Mohsen AH, McKendrick MW, Schmid ML, Green ST, Hadjivassiliou M, Romanowski C. Postmalaria neurological syndrome: a case of acute disseminated encephalomyelitis? J Neurol Neurosurg Psychiatry. 2000;68:388-9.

66. van der Wal G, Verhagen WIM, Dofferhoff ASM. Neurological complications following Plasmodium falciparum infection. Neth J Med. 2005;63:180-3.

67. Zambito Marsala S, Ferracci F, Cecotti L, Gentile M, Conte F, Candeago RM, et al. Post-malaria neurological syndrome: clinical and laboratory findings in one patient. Neurol Sci. 2006;27:442-4.

68. Markley JD, Edmond MB. Post-malaria neurological syndrome: a case report and review of the literature. J Travel Med. 2009;16:424-30.

69. Rakotoarivelo RA, Razafimahefa SH, Andrianasolo R, Fandresena FH, Razanamparany MMO, Randria MJD, et al. Post-malaria neurological syndrome complicating a Plasmodium falciparum malaria in Madagascar. Bull Soc Pathol Exot. 2012;105:199-201 (in French)

70. Prendki V, Elzière C, Durand R, Hamdi A, Cohen Y, Onnen I, et al. Postmalaria neurological syndrome - two cases in patients of African origin. Am J Trop Med Hyg. 2008;78:699-701.

71. Mizuno Y, Kato Y, Kanagawa S, Kudo K, Hashimoto M, Kunimoto M, et al. A case of postmalaria neurological syndrome in Japan. J Infect Chemother. 2006:12:399-401.

72. Freitas DRC, Santos JB, Castro CN. Healing with malaria: a brief historical review of malariotherapy for neurosyphilis, mental disorders and other infectious diseases. Rev Soc Bras Med Trop. 2014;47:260-1.

73. British Medical Journal. Treatment of mental disease. Morison lectures, 1929. Br Med J. 1929:1:1135-36.

74. Chernin E. The malaria therapy of neurosyphilis. J Parasitol. 1984;70:611-7.

75. Wagner-Jauregg $J$. The treatment of general paresis by inoculation of malaria. J Nerv Ment Dis. 1922;55:369-75.

76. The Scientific Monthly. Professor J. Von Wagner-Jauregg: Nobel Prize Winner, 1927. Sci Mon. 1927:26:190-2.

77. Howes OD, Khambhaita A, Fusar-Poli P. Julius Wagner-Jauregg, 1857-1940. Am J Psychiatry. 2009:166:409.

78. Gartlehner G, Stepper K. Julius Wagner-Jauregg: pyrotherapy, simultanmethode, and "racial hygiene". J R Soc Med. 2012;105:357-9.

79. Delgado HF. The treatment of paresis by inoculation with malaria. J Nerv Ment Dis. 1922;5:376-89.

80. Grant AR. The treatment of general paralysis by malaria. BMJ. 1923;2:698-700

81. McAlister W. The treatment of general paralysis by infection with malaria. BMJ. 1923;2:696-8.

82. Macbride HJ, Templeton WL. The treatment of general paralysis of the insane by malaria. J Neurol Psychopathol. 1924;5:13-27.

83. Templeton WL. The treatment of general paralysis by malaria. BMJ. 1923;1:895-6.

84. Scripture EW. Treatment of general paralysis by malaria. BMJ. 1922:2:1197.

85. British Medical Journal. The first international malaria congress. BMJ. 1925;2:970-1.

86. Pool A. Dementia Paralytica: therapeutic measures and results. J Neurol Psychopathol. 1929;10:21-32

87. British Medical Journal. Treatment of general paralysis by malaria. BMJ. 1923;1:908

88. Yorke W. The malaria treatment of general paralysis. Nature. 1924;114:615-6.

89. The Science News-Letter. Prize method used here. Sci News Lett. 1927;12:393. 
90. Worster-Drought C, Beccle HC. The treatment of general paralysis of the insane by pyrotherapy. BMJ. 1929;2:1256-7.

91. Lees R. Treatment of general paralysis of the insane by induced malaria: note on fifty cases. BMJ. 1931;2:336-9.

92. Crawford CM. Treatment of paretic neurosyphilis by malaria and tryparsamide. Can J Public Health. 1940;31:99-105.

93. Nicol WD. Treatment of G.P.I. BMJ. 1938;2:1012.

94. Rudolf GDM. Recent advances in therapeutic (induced) malaria. J Neurol Psychopathol. 1936;16:239-55.

95. British Medical Journal. Malarial therapy and the community. BMJ. 1933:2:539.

96. British Medical Journal. Treatment of general paralysis by malaria. BMJ. 1924;1:289.

97. British Medical Journal. Treatment of general paralysis by malaria. BMJ. 1924;1:479.

98. Clark RM. Treatment of general paralysis by malaria. BMJ. 1925;1:600.

99. British Medical Journal. Therapeutic malaria. BMJ. 1927;2:831-2.

100. Mayne B. The injection of mosquito sporozoites in malaria therapy. Public Health Rep. 1933;48:909-16.

101. British Medical Journal. Malaria therapy. BMJ. 1938;2:796.

102. Greenwood D. Conflicts of interest: the genesis of synthetic antimalarial agents in peace and war. J Antimicrob Chemother. 1995;36:857-72.

103. Dixon AWE, Ramsden W, Acton HW, Garrod AE, Hele TS, Nierenstein M, et al. Discussion on quinine and its related alkaloids in pharmacology and therapeutics. BMJ. 1920;2:113-21.

104. Rieckmann KH, Powell RD, McNamara JV, Willerson D, Lass L, Frischer $\mathrm{H}$, et al. Effects of tetracycline against chloroquine-resistant and chloroquine-sensitive Plasmodium falciparum. Am J Trop Med Hyg. 1971:20:811-5.

105. Clyde DF, Miller RM, DuPont HL, Hornick RB. Antimalarial effects of tetracyclines in man. J Trop Med Hyg. 1971;74:238-42.

106. Jiang JB, Li GQ, Guo XB, Kong YC, Arnold K. Antimalarial activity of mefloquine and qinghaosu. Lancet. 1982;2:285-8.

107. Arnold K. Qinghaosu and derivatives in the treatment of malaria-a personal review. J Hong Kong Med Assoc. 1993:45:189-96.

108. McNeil DG. For intrigue, malaria drug gets the prize. In: The New York times. 2012. http://www.nytimes.com/2012/01/17/health/for-intriguemalaria-drug-artemisinin-gets-the-prize.html. Accessed 16 Feb 2016.

109. Sullivan DJ. Cinchona Alkaloids: Quinine and Quinidine. In: Staines HM, Krishna S, editors. Treatment and prevention of malaria. Basel: Springer Basel; 2012. p. 45-68.

110. Kritzer JH. Quinine-cinchona. In: Haskel Kritzer J, editor. Text-book of iridiagnosis: guide in treatment. Chicago: J. Hazkel Kritzer. 1921. p. 81-8.

111. Mishra KC. Delirium after quinine administration. Antiseptic. 1947:44:614.

112. Prasad RS, Kodali VRR, Khuraijam GS, Cho M, Travers JP. Acute confusion and blindness from quinine toxicity. Eur J Emerg Med. 2003;10:353-6.

113. Billig N, Buongiorno P. Quinidine-induced organic mental disorders. J Am Geriatr Soc. 1985;33:504-6.

114. Quintanilla J. Psychosis due to quinidine intoxication. Am J Psychiatry. 1957:113:1031-2.

115. Deleu D, Schmedding E. Acute psychosis as idiosyncratic reaction to quinidine: report of two cases. BMJ. 1987;294:1001-2.

116. Summers WK, Allen RE, Pitts FN. Does physostigmine reverse quinidine delirium? West J Med. 1981;135:411-4.

117. Johnson AG, Day RO, Seldon WA. A functional psychosis precipitated by quinidine. Med J Aust. 1990;153:47-9.

118. Gilbert GJ. Quinidine dementia. Am J Cardiol. 1978;41:791

119. von Oettingen W. Acridine dyes. In: The therapeutic agents of the quinoline group. New York: The Chemical Catalog Company; 1933. p. 239-55.

120. Russell PF. Plasmochin, plasmochin with quinine salts and atabrine in malaria therapy. Arch Intern Med. 1934;53:309-20.

121. British Medical Journal. Quinine and World War. Br Med J. 1942;1:152-3.

122. de Mello IF. Chemoprophylaxis of malaria in Portugese India. SuidAfrikaanse Tydskr vir Geneeskd. 1938;12:710-24.

123. Ad A, Needham DE. More observations on atebrin. Lancet. 1933:222:929-30

124. Kingsbury AN. Psychoses in cases of malaria following exhibition of atebrin. Lancet. 1934;224:979-82.

125. Govindaswamy MV. Atebrin poisoning. Lancet. 1936;227:56-7.
126. Winthrop Chemical Company. Malaria: chemotherapy with atabrine. New York: Winthrop Chemical Company; 1938.

127. The Science News-Letter. New anti-malarial drugs announced ahead of time. Sci News Lett. 1942;42:108.

128. Baxter JP. Antimalarials. In: Scientists against time. Boston: Little, Brown and Company; 1946. p. 299-320.

129. Committee on Medical Research of the Office of Scientific Research and Development. Minutes of meeting of atabrine conference held at the national academy of sciences November 2, 1942. In: Bulletin of malaria research, vol 1. Washington, DC: Board for the Coordination of Malarial Studies; 1942. p. 46a-f.

130. Clark WM. History of the co-operative wartime program. In: Wiselogle FY, editor. A survey of antimalarial drugs, 1941-1945, vol. 1. Ann Arbor: J.W. Edwards; 1946. p. 2-57.

131. Temkin O, Ramsey EM. Antimalarial drugs: summary of classified material on file. Washington, DC: National Research Council; 1944.

132. Loughlin EH, Bennett RH, Santora E, Mattucci S. Clinical toxicity of atabrine dihydrochloride. War Med. 1943:4:272-9.

133. Carden GA. Introduction. In: Malaria reports, vol 1. Washington, DC: Board for the Coordination of Malarial Studies; 1946. p. i-xX.

134. Newell HW, Lidz T. Malaria report \#180: a clinical study of the toxicity of atabrine on the central nervous system. In: Reports Malaria, editor. Vol 2. Washington, DC: Board for the Coordination of Malarial Studies; 1944. p. $1-2$.

135. Newell HW, LidzT. The toxicity of atabrine to the central nervous system. Am J Psychiatry. 1946;102:805-18.

136. Sheppeck ML, Wexberg LE. Malaria Report \#A-196: abstract of report on toxic psychoses associated with administration of atabrine from an overseas hospital. In: Malaria reports, vol 2. Washington, DC: Board for the Coordination of Malarial Studies; 1944. p. 1-2.

137. Gaskill HS, Fitz-Hugh T. Toxic psychoses following atabrine. Bull US Army Med Dep. 1945;86:63-9.

138. LidzT, Kahn RL. Toxicity of quinacrine (atabrine) for the central nervous system; an experimental study on human subjects. Arch Neurol Psychiatry. 1946;56:284-99.

139. US Army Medical Deparment. Malaria Report \#181: experimental study of the toxicity of atabrine to the human central nervous system. In: Malaria reports, vol 2. Washington, DC: Board for the Coordination of Malarial Studies; 1944. p. 2-5.

140. Engel GL, Romano J, Ferris EB. Effect of quinacrine (atabrine) on the central nervous system; clinical and electroencephalographic studies. Arch Neurol Psychiatry. 1947;58:337-50.

141. Engel GL, Romeno J, Ferris EB, Schmidt LH. Malaria report \#212: the effect of atabrine on the central nervous system. In: Malaria reports, vol 2. Washington, DC: Board for the Coordination of Malarial Studies; 1944. p. $1-4$

142. Engel GL, Romano J, Ferris EB. Malaria report \#266: the effect of atabrine on the central nervous system. In: Malaria reports, vol 3. Washington, DC: Board for the Coordination of Malarial Studies; 1944. p. 1-4.

143. Lull GF. Reactions attributed to atabrine. J Mil Med Pac. 1945;1:1-4.

144. McIntire RT. Treatment of clinical malaria. Navy Dep BUMED News Lett. 1944:4:17-25

145. Peal S. Psychiatric experiences in a tropical theater of operations. Bull US Army Med Dep. 1944;73:68-78.

146. Greiber MF. Psychoses associated with the administration of atabrine. Am J Psychiatry. 1947;104:306-14.

147. Shiers D. Cerebral excitement following mepacrine therapy. BMJ. 1946;1:762-3

148. Mergener JC. Psychosis following administration of quinacrine hydrochloride for malaria; neuropsychiatric study of a case. War Med. 1945:8:250-2.

149. Sheppeck ML, Wexberg LE. Toxic psychoses associated with administration of quinacrine. Arch Neurol Psychiatry. 1946;55:489-510.

150. Ocko FH. A case of atabrine psychosis in a civilian. Am J Psychiatry. 1947;103:833

151. Kapur KB, Das Gupta PR. Sexual disorder in "mepacrine psychoses". Indian Med Gaz. 1950;85:20-2.

152. Hoobler SW. Psychotic reactions to the ingestion of large doses of quinacrine in normal subjects. Am J Trop Med Hyg. 1947;27:477-81.

153. Coatney GR. Pitfalls in a discovery: the chronicle of chloroquine. Am J Trop Med Hyg. 1963;12:121-8. 
154. Pou S, Winter RW, Nilsen A, Kelly JX, Li Y, Doggett JS, et al. Sontochin as a guide to the development of drugs against chloroquine-resistant malaria. Antimicrob Agents Chemother. 2012;56:3475-80.

155. Southworth H. C.I.O.S. target number $24 / 3$ medical. In: Farben IG, editor. Clinical testing of antimalarials. London: His Majesty's Stationery Office; 1945.

156. Berliner R, Butler T. Summary of data on the drugs tested in man. In: Wiselogle FY, editor. A survey of antimalarial drugs, 1941-1945, vol. 1. Ann Arbor: J.W. Edwards; 1946. p. 221-451.

157. Ruhe DS, Cooper WC. Studies in human malaria; the protective and therapeutic action of SN 6911 against St. Elizabeth strain vivax malaria. Am J Hyg. 1949;49:41-8.

158. Board for the Coordination of Malarial Studies. Minutes of the meeting of the board for the coordination of malarial studies 25 July 1945. In: Bulletin of malaria research, vol 2. Washington, DC: Board for the Coordination of Malarial Studies; 1945. p. 1259-63.

159. The Science News-Letter. Better antimalarial drug. Sci News Lett. 1946:49:30-1.

160. Manwell RD. Malaria, birds, and war. Am Sci. 1949;37:60-8

161. Malaria Subcommittee of the Colonial Medical Research Committee. Use of antimalarial drugs. recommendations on the use of antimalarial drugs. BMJ. 1954;2:148-50.

162. Covell G. Malaria: its recognition, treatment, and prevention. BMJ. 1951:2:1021-5.

163. Reis J. Insomnia induced by chloroquine in the treatment of lupus erythematosus disseminatus. Presse Médicale. 1991;20:659 (in French)

164. Bhatia MS. Chloroquine-induced recurrent psychosis (brief report). Indian J Med Sci. 1996;50:302-4.

165. Maxwell NM, Nevin RL, Stahl S, Block J, Shugarts S, Wu AHB, et al. Prolonged neuropsychiatric effects following management of chloroquine intoxication with psychotropic polypharmacy. Clin Case Rep. 2015;3:379-87.

166. Brookes DB. Chloroquine psychosis. BMJ. 1966;1:983.

167. Mohan D, Mohandas E, Rajat R. Chloroquine psychosis: a chemical psychosis? J Natl Med Assoc. 1981;73:1073-6.

168. Rab SM. Two cases of chloroquine psychosis. BMJ. 1963;1:1275.

169. Bhatia MS, Dhar NK, Singhal PK. Capgras'syndrome in chloroquine induced psychosis. Indian Pediatr. 1988;25:905-6.

170. Bhatia MS, Singhal PK, Agrawal P, Malik SC. Capgras syndrome in chloroquine induced psychosis. Indian J Psychiatry. 1988;30:311-3.

171. Sapp OL. Toxic psychosis due to quinacrine and chloroquine. JAMA. 1964;187:373-5.

172. Mustakallio KK, Pihkanen TA, Putkonen T. Toxic psychosis during chloroquine treatment. Ann Med Intern Fenn. 1962;51:223-8.

173. Bogaczewicz J, Sobow T, Bogaczewicz A, Robak E, Bienkowski P, SysaJedrzejowska A, et al. Exacerbations of bipolar disorder triggered by chloroquine in systemic lupus erythematosus - a case report. Lupus. 2014;23:188-93.

174. Good MI, Shader RI. Behavioral toxicity and equivocal suicide associated with chloroquine and its derivatives. Am J Psychiatry. 1977;134:798-801.

175. Good MI, Shader RI. Lethality and behavioral side effects of chloroquine J Clin Psychopharmacol. 1982;2:40-7.

176. Jousset N, Rougé-Maillart C, Turcant A, Guilleux M, Le Bouil A, Tracqui A. Suicide by skull stab wounds: a case of drug-induced psychosis. Am J Forensic Med Pathol. 2010;31:378-81.

177. Burrell ZL, Martinez AC. Chloroquine and hydroxychloroquine in the treatment of cardiac arrhythmias. N Engl J Med. 1958;258:798-800.

178. Sahoo S, Kumar M, Sinha VK. Chloroquine-induced recurrent psychosis. Am J Ther. 2007;14:406-7.

179. Ragan E, Wilson R, Li F, Spasoff R, Bigelow G, Spinner N. Psychotic symptoms in volunteers serving overseas. Lancet. 1985;2:37.

180. Biswas PS, Sen D, Majumdar R. Psychosis following chloroquine ingestion: a 10-year comparative study from a malaria-hyperendemic district of India. Gen Hosp Psychiatry. 2014;36:181-6.

181. Telgt DS, van der Ven AJ, Schimmer B, Droogleever-Fortuyn HA, Sauerwein RW. Serious psychiatric symptoms after chloroquine treatment following experimental malaria infection. Ann Pharmacother. 2005:39:551-4

182. Cras P, Martin JJ. Transient global amnesia following ingestion of chloroquine. J Neurol Neurosurg Psychiatry. 1990;53:926.
183. Stuiver PC, Ligthelm RJ, Goud TJ. Acute psychosis after mefloquine. Lancet. 1989:2:282.

184. Garg P, Mody P, Lall KB. Toxic psychosis due to chloroquine. Indian J Pediatr. 1990;57:133-4.

185. Collins GB, MCAllister MS. Chloroquine psychosis masquerading as PCP: a case report. J Psychoactive Drugs. 2008;40:211-4.

186. Modell W. Malaria and victory in Vietnam. Science. 1968;162:1346-52.

187. Tigertt WD. The army malaria research program. Ann Intern Med. 1969;70:150-3.

188. Croft AM. A lesson learnt: the rise and fall of Lariam and Halfan. J R Soc Med. 2007;100:170-4

189. Nevin RL. Mefloquine and posttraumatic stress disorder. In: Ritchie EC editor. Textbook of military medicine. Forensic and ethical issues in military behavioral health. Washington, DC: Borden Institute; 2015. p. 277-96.

190. Nevin RL, Byrd AM. Neuropsychiatric adverse reactions to mefloquine: a sysmetic comparison of prescribing and patient safety guidance in the US, UK, Ireland, Australia, New Zealand, and Canada. Neurol Ther. 2016. doi:10.1007/s40120-016-0045-5.

191. Ritchie EC, Block J, Nevin RL. Psychiatric side effects of mefloquine: applications to forensic psychiatry. J Am Acad Psychiatry Law. 2013:41:224-35.

192. Recasens C, Zittoun C, Féline A. A psychotic episode in a patient coming home from Africa: the possible role of mefloquine. Ann Psychiatr. 1993:8:100-3 (in French)

193. Hennequin C, Bourée P, Bazin N, Bisaro F, Feline A. Severe psychiatric side effects observed during prophylaxis and treatment with mefloquine. Arch Intern Med. 1994;154:2360-2.

194. Oueriagli Nahib F, Touhami M, Laffinti A, Abilkacem L. Mood disorder after malaria prophylaxis with mefloquine (two case reports). Encephale. 2011;37:393-6 (in French).

195. Colebunders R. Cured of fear of flying. Travel Med Infect Dis. 2011;9:82

196. Clattenburg RN, Donnelly CL. Case study: neuropsychiatric symptoms associated with the antimalarial agent mefloquine. J Am Acad Child Adolesc Psychiatry. 1997:36:1606-8.

197. Weinke T, Trautmann M, Held T, Weber G, Eichenlaub D, Fleischer K, et al Neuropsychiatric side effects after the use of mefloquine. Am J Trop Med Hyg. 1991;45:86-91.

198. Nevin RL. Limbic encephalopathy and central vestibulopathy caused by mefloquine: a case report. Travel Med Infect Dis. 2012;10:144-51.

199. Tran TM, Browning J, Dell ML. Psychosis with paranoid delusions after a therapeutic dose of mefloquine: a case report. Malar J. 2006:5:74.

200. Dietz A, Frölich L. Mefloquine-induced paranoid psychosis and subsequent major depression in a 25-year-old student. Pharmacopsychiatry. 2002;35:200-2.

201. Peterson AL, Seegmiller RA, Schindler LS. Severe neuropsychiatric reaction in a deployed military member after prophylactic mefloquine. Case Rep Psychiatry. 2011;2011:350417.

202. Tor PC, Lee HY, Tan CH. Mefloquine-induced mania in a 22-year-old Chinese man. Singapore Med J. 2006;47:549-50.

203. Folkerts $\mathrm{H}$, Kuhs H. [Psychotic episode caused by prevention of malaria with mefloquine. A case report. Nervenarzt. 1992;63:300-2 (in German).

204. Piening RB, Young SA. Mefloquine-induced psychosis. Ann Emerg Med. 1996;27:792-3.

205. Nevin RL. Organic depersonalization as a chronic sequela of mefloquine intoxication. Psychosomatics. 2015;56:103-5.

206. Carme B, Nevez G, Peguet C, Bories C, Andrejak M. Neuropsychiatric intolerance during mefloquine prophylaxis. 5 case reports. Médecine Mal Infect. 1996:26:728-9 (in French).

207. van Puijenbroek EP, Meyboom RHB. Sleep disorders during mefloquine use. Pharmaceutisch Weekblad. 1995:130:477-9 (in Dutch)

208. Chester AC, Sandroni P. Case report: peripheral polyneuropathy and mefloquine prophylaxis. Am J Trop Med Hyg. 2011;85:1008-9.

209. Boudreau E, Schuster B, Sanchez J, Novakowski W, Johnson R, Redmond D, Hanson R, Dausel L. Tolerability of prophylactic Lariam regimens. Trop Med Parasitol. 1993;44:257-65.

210. Burke BM. Mefloquine. Lancet. 1993;341:1605-6.

211. Arznei-Telegramm. Psychoses, suicides, etcetera. Should mefloquine (Lariam) still be allowed? Arznei-Telegramm. 2002;33:89. 
212. Nevin RL. Hallucinations and persecutory delusions in mefloquineassociated suicide. Am J Forensic Med Pathol. 2012;33:e8.

213. Scrip. Roche's Lariam linked to a suicide in UK. Scrip. 1998;2321:23.

214. Nevin RL, Ritchie EC. The mefloquine intoxication syndrome: A signifcant potential confounder in the diagnosis and management of PTSD and other chronic deployment-related neuropsychiatric disorders. In: Ritchie EC, editor. Posttraumatic stress disorder and related disorders in combat veterans. Cham: Springer International Publishing; 2015. p. 257-78.

215. Nevin RL. Issues in the prevention of malaria among women at war. In Ritchie EC, Naclerio AL, editors. women at war. London: Oxford University Press; 2015. p. 93-119.

216. Keystone JS, Kain K. Mefloquine dangers_fact or fancy? Can J Infect Dis. 1995:6:14-5.

217. Lobel HO. Adverse health events and malaria prophylaxis. Healthwise Newsl Peace Corps Med Off Worldw. 1996;5:1-4.

218. Schlagenhauf $P$, Steffen R. Neuropsychiatric events and travel: do antimalarials play a role? J Travel Med. 2000;7:225-6.

219. Levin A. FDA warning highlights mefloquine's mental health risks. Psychiatric News. 2013:48:1.

220. Ringqvist $\AA$, Bech P, Glenthøj B, Petersen E. Acute and long-term psychiatric side effects of mefloquine: a follow-up on Danish adverse event reports. Travel Med Infect Dis. 2015;13:80-8.

221. World Health Organization. Post-malaria neurological syndrome and mefloquine. WHO Drug Inf. 1996;10:177.

222. The Science News-Letter. Germany's new scientific researches reported. Synthetic rival to quinine. Sci News Lett. 1926;10:3.

223. British Medical Journal. A synthetic remedy for malaria. BMJ. 1926;2:798-9.

224. Hardgrove M, Applebaum IL. Plasmochin toxicity; analysis of 258 cases. Ann Intern Med. 1946;25:103-12.

225. Loken AC, Haymaker W. Pamaquine poisoning in man, with a clinicopathologic study of one case. Am J Trop Med Hyg. 1949;29:341-52.

226. Schmidt IG, Schmidt LH. Neurotoxicity of the 8-aminoquinolines. I. Lesions in the central nervous system of the Rhesus monkey induced by administration of plasmocid. J Neuropathol Exp Neurol. 1948;7:368-98.

227. Schmidt IG, Schmidt LH. Neurotoxicity of the 8-aminoquinolines. II. Reactions of various experimental animals to plasmocid. J Comp Neurol. 1949;91:337-67.

228. Schmidt IG, Schmidt LH. Neurotoxicity of the 8-aminoquinolines. III. The effects of pentaquine, isopentaquine, primaquine, and pamaquine on the central nervous system of the rhesus monkey. J Neuropathol Exp Neurol. 1951:10:231-56.

229. West JB, Henderson AB. Plasmochin intoxication. Bull US Army Med Dep. 1944:82:87-99.

230. Findlay GM. Toxic reactions to antimalarial drugs. In: Findlay GM, editor. Recent advances in chemotherapy, vol. 2. Philadelphia: The Blakiston Company; 1950. p. 187-269.

231. Hill DR, Baird JK, Parise ME, Lewis LS, Ryan ET, Magill AJ. Primaquine: report from CDC expert meeting on malaria chemoprophylaxis I. Am J Trop Med Hyg. 2006;75:402-15.

232. Schlossberg D. Reaction to primaquine. Ann Intern Med. 1980:92:435

233. Vale N, Moreira R, Gomes P. Primaquine revisited six decades after its discovery. Eur J Med Chem. 2009;44:937-53.

234. Renslo AR. Antimalarial drug discovery: from quinine to the dream of eradication. ACS Med Chem Lett. 2013:4:1126-8.

235. Nasveld PE. Tafenoquine in the prophylaxis and treatment of malaria in Australian defence force personnel [Thesis]. James Cook University. 2011

236. Milhous WK. Development of new drugs for chemoprophylaxis of malaria. Médecine Trop. 2001;61:48-50.

237. Walsh DS, Looareesuwan S, Wilairatana P, Heppner DG, Tang DB, Brewer $\mathrm{TG}$, et al. Randomized dose-ranging study of the safety and efficacy of WR 238605 (Tafenoquine) in the prevention of relapse of Plasmodium vivax malaria in Thailand. J Infect Dis. 1999:180:1282-7.

238. Nasveld PE, Edstein MD, Reid M, Brennan L, Harris IE, Kitchener SJ, et al. Randomized, double-blind study of the safety, tolerability, and efficacy of tafenoquine versus mefloquine for malaria prophylaxis in nonimmune subjects. Antimicrob Agents Chemother. 2010;54:792-8.
239. Charles BG, Miller AK, Nasveld PE, Reid MG, Harris IE, Edstein MD. Population pharmacokinetics of tafenoquine during malaria prophylaxis in healthy subjects. Antimicrob Agents Chemother. 2007;51:2709-15.

240. Bunnag D, Karbwang J, Viravan C, Chitamas S, Harinasuta T. Clinical trials of mefloquine with tetracycline. Southeast Asian J Trop Med Public Health. 1992;23:377-82.

241. Willerson D, Rieckmann KH, Carson PE, Frischer H. Effects of minocycline against chloroquine-resistant falciparum malaria. Am J Trop Med Hyg. 1972;21:857-62.

242. Gaillard T, Madamet M, Pradines B. Tetracyclines in malaria. Malar J. 2015:14:445.

243. Tan KR, Magill AJ, Parise ME, Arguin PM. Doxycycline for malaria chemoprophylaxis and treatment: report from the CDC expert meeting on malaria chemoprophylaxis. Am J Trop Med Hyg. 2011;84:517-31.

244. Grabias B, Kumar S. Adverse neuropsychiatric effects of antimalarial drugs. Expert Opin Drug Saf. 2016. doi:10.1080/14740338.2016.1175428.

245. Wallace MR, Sharp TW, Smoak B, Iriye C, Rozmajzl P, Thornton SA, et al. Malaria among United States troops in Somalia. Am J Med. 1996;100:49-55

246. Ohrt C, Richie TL, Widjaja H, Shanks GD, Fitriadi J, Fryauff DJ, et al. Mefloquine compared with doxycycline for the prophylaxis of malaria in Indonesian soldiers. A randomized, double-blind, placebo-controlled trial. Ann Intern Med. 1997;126:963-72.

247. Atigari OV, Hogan C, Healy D. Doxycycline and suicidality. BMJ Case Rep. 2013;2013:2013-5.

248. Taylor WRJ, White N. Antimalarial drug toxicity: a review. Drug Saf. 2004:27:25-61.

249. Alkadi HO. Antimalarial drug toxicity: a review. Chemotherapy. 2007:53:385-91.

250. Steffen R, Fuchs E, Schildknecht J, Naef U, Funk M, Schlagenhauf P, et al. Mefloquine compared with other malaria chemoprophylactic regimens in tourists visiting east Africa. Lancet. 1993;341:1299-303.

251. Briand V, Bottero J, Noël H, Masse V, Cordel H, Guerra J, et al. Intermittent treatment for the prevention of malaria during pregnancy in Benin: a randomized, open-label equivalence trial comparing sulfadoxinepyrimethamine with mefloquine. J Infect Dis. 2009;200:991-1001.

252. Boggild AK, Parise ME, Lewis LS, Kain KC. Atovaquone-proguanil: report from the CDC expert meeting on malaria chemoprophylaxis (II). Am J Trop Med Hyg. 2007;76:208-23.

253. Overbosch D, Schilthuis H, Bienzle U, Behrens RH, Kain KC, Clarke PD, et al. Atovaquone-proguanil versus mefloquine for malaria prophylaxis in nonimmune travelers: results from a randomized, double-blind study. Clin Infect Dis. 2001;33:1015-21.

254. Camus D, Djossou F, Schilthuis HJ, Høgh B, Dutoit E, Malvy D, et al. Atovaquone-proguanil versus chloroquine-proguanil for malaria prophylaxis in nonimmune pediatric travelers: results of an international, randomized, open-label study. Clin Infect Dis. 2004;38:1716-23.

255. Brewer TG, Grate SJ, Peggins J, Peter J, Petras JM, Levine BS, et al. Fatal neurotoxocity of arteether and artemether. Am J Trop Med Hyg. 1994:51:251-9.

256. Toovey S. Are currently deployed artemisinins neurotoxic? Toxicol Lett. 2006;166:95-104.

257. Genovese RF, Newman DB. Understanding artemisinin-induced brainstem neurotoxicity. Arch Toxicol. 2008:82:379-85.

258. Medhi B, Patyar S, Rao RS, Byrav DSP, Prakash A. Pharmacokinetic and toxicological profile of artemisinin compounds: an update. Pharmacology. 2009:84:323-32.

259. Martín VR, Martínez CG, Mackenzie I, Schmutzhard J, Pace C, Lalloo DG, et al. Neuroauditory toxicity of artemisinin combination therapies-have safety concerns been addressed? Am J Trop Med Hyg. 2014;91:62-73.

260. Sinclair D, Zani B, Donegan S, Olliaro P, Garner P. Artemisinin-based combination therapy for treating uncomplicated malaria. Cochrane Database Syst Rev. 2009;(3):CD007483. doi:10.1002/14651858. CD007483.pub2.

261. Banek K, Lalani M, Staedke SG, Chandramohan D. Adherence to artemisinin-based combination therapy for the treatment of malaria: a systematic review of the evidence. Malar J. 2014;13:7.

262. Angus B. Novel anti-malarial combinations and their toxicity. Expert Rev Clin Pharmacol. 2014;7:299-316. 